\title{
VIDEOTAPING IN THE FOREIGN LANGUAGE CLASSROOM
}

by Shirley Jane Kaub

Are many of us overlooking a useful instructional tool in the foreign language classroom? At a recent "national" symposium on multi-media in foreign language teaching, the uses of the language laboratory per se and its variants, as well as the tape recorder, the film projector, the overhead projector, and even the more exotic equipment such as the computer were demonstrated. But there is a piece of equipment more accessible to most of us than the computer and more versatile than the audiotape recorder, the slide and movie projector and the overhead: the videotape recorder and player.

We are told that a film should be viewed more than once; this is not always feasible by the rental terms. A videotape may be shown any number of times and then filed permanently or reused/Taping makes available native speakers, specialists, master teachers, and members of teams particularly effective in certain areas at times when a "live" presentation may not be possible for all groups and individuals. And what is a greater motivation for the student than actually to see himself on the screen? Consider the following:

STUDENT RECORDINGS (suggested from an infinite number of possibilities):

- Memorized dialogs in prereading or later stages of learning.

- Short original dialogs, presentations of story or vocabulary, "commercials," all in the target language.

- Topics on special subjects given in small groups and reshown to other groups. Recording of report by one or more students may be part of the activities of individualized learning packages.

\section{$\checkmark$ INSTRUCTIONAL RECORDINGS:}

- Regular TV programs dealing with target cultures and countries taped for later viewing by large groups (with written permission of network).

- Sounds of language and actual facial movements necessary recorded by natives (especially useful for small groups on first level).

- Kinetic patterns in target language recorded by natives for viewing and discussion. 
- Talks by native speakers in target language (can be replayed after discussion).

- Stills put into a unit concept for stimulation about a target culture.

- Teaching programs on production of graphics (e.g., Russian script, Chinese ideographs), on reading handwritten scripts (for advanced students), etc.

- Supplementary programs, such as tapes on African literature in the target language, the contribution of the target culture to American life, etc.

$\angle$ Recording is useful, too, for more objective evaluation, particularly in the area of the speaking skill $>$ Instead of being under the pressure of making forced judgments in the classroom, the teacher may view the performance as often as necessary. The tape may be discussed with the student just as written work may be examined. $<$ Videotape is far more effective than audiotape in that speech in a target language should be accompanied by appropriate gestures,>

$<$ Videotaping finds many uses in in-service work $<$ Presentations of beginning teachers and practice teachers or micro-teaching of certain concepts may be taped for later discussion or self-evaluation; segments of classroom work may be recorded for coding in interaction analysis. While class visitation by beginning teachers with follow-up discussion is desirable, schedules do not always permit observation of particular classes. As a substitute, recordings by a master teacher may be filed for later viewing and discussion. Topics might include:

- Use of overhead projector and other visuals (e.g., loop film).

- Examples of various types of drill (substitution, transformation, etc.)

- Presentation of different structural concepts.

- Oral testing procedures for specific skills or concepts.

Understandably, many teachers are reluctant to agree to taping or feel inhibited by the procedure. (Students are usually interested and motivated.) More frequent use of videotape equipment, however, may overcome some of these difficulties. Especially as flexible scheduling and independent study become increasingly important in our planning, videotaping should find more and more place in foreign language learning.

\section{ABOUT THE AUTHOR:}

Shirley Jane Kaub is the Coordinator of Foreign Languages for the Madison, Wisconsin Public Schools. 